\title{
O MERCADO DE CARBONO NA POLÍTICA DE MITIGAÇÃO DAS MUDANÇAS CLIMÁTICAS.
}

\author{
Beatriz Bergamim Duarte ${ }^{1}$ \\ Lise Tupiassu ${ }^{2}$ \\ Simone Nobre ${ }^{3}$
}

\section{RESUMO}

O artigo tem como objetivo analisar como se desenvolve o mercado de carbono, a nível global e nacional, de modo a explicar como a operacionalização deste instrumento promove o desenvolvimento de uma política de redução das emissões e proteção contra as mudanças climáticas. Foi utilizada a pesquisa bibliográfica e documental resultando com abordagem descritiva. Primeiramente discorre-se sobre a origem do Mercado de Carbono, a fim de analisar os acordos que trouxeram a sua institucionalização. $\mathrm{O}$ texto traz, em seguida, a forma como o mercado se desenvolve em nível global, e, enfim, no cenário nacional, tratando de suas particularidades e desafios

Palavras chave: MDL, REDD, Meio ambiente, política ambiental, créditos de carbono

\section{THE CARBON MARKET IN CLIMATE CHANGE MITIGATION POLICY}

\begin{abstract}
The article aims to analyze how the carbon market develops, globally and nationally, in order to explain how the operationalization of this instrument promotes the development of a policy to reduce emissions and protect against climate change. Bibliographic and documentary research was used, resulting in a descriptive approach. Firstly, the origin of the Carbon Market is discussed, in order to analyze the agreements that brought its institutionalization. The text then shows how the market develops at a global level, and, finally, on the national scene, dealing with its particularities and challenges.
\end{abstract}

Keywords: MLD, REDD, Environment, environmental policy, carbon credits

\section{Introdução}

A ampla exploração dos recursos naturais pelo homem, principalmente após a Revolução Industrial, causou uma intensificação do debate em âmbito global em relação à

\footnotetext{
1 Advogada. Mestranda em Direito Ambiental e Direitos Humanos no Programa de Pós-Graduação da Universidade Federal do Pará - UFPA. E-mail: beatrizbergamim@ hotmail.com

${ }^{2}$ Doutora em Direito Público pela Université Toulouse 1. Mestre em Direito Tributário pela Université Paris 1 Panthéon/Sorbonne e em Instituições Jurídico-Políticas pela UFPA. Professora da UFPA e CESUPA. Procuradora Federal. E-mail: ltupiassu@gmail.com

${ }^{3}$ Mestre em Direito pelo Centro Universitário do Estado do Pará. Doutoranda em Direito pela Universidade Federal do Pará. Auditora Fiscal da Secretaria de Estado de Fazenda do Pará. E-mail: simonecruznobre2020@gmail.com
} 
questão ambiental, sobretudo no que diz respeito a necessidade da preservação da natureza para a sobrevivência do homem, diante da relação de dependência do uso de recursos naturais pelo homem para a concretização de suas atividades habituais (FREITAS, 2012).

Dentro dessa questão ambiental, as questões climáticas ganharam um imperioso destaque, tendo em vista as ações humanas de ampla poluição do planeta pela emissão de Gases do Efeito Estufa (GEE), o que traz como consequência o aquecimento global, gerando diversos malefícios para o meio ambiente e seus recursos naturais. Diante disso, se fez necessário uma governança ambiental global voltada para políticas de redução das emissões dos GEEs, a fim de que os países realizassem ações para a proteção do meio ambiente contra a poluição, bem como prevenir que maiores danos viessem a acontecer (VIOLA, 2002).

Assim, houve a criação de diversos acordos, com o objetivo de tratar sobre a responsabilidade dos países quanto a redução das emissões dos Gases do Efeito Estufa. Dentre eles, se destacam a Convenção Quadro das Nações Unidades sobre Mudanças Climática (CQNUMC), assinada na Rio -92, em 1992 (ONU, 1992) e o Protocolo de Kyoto em 1997.

O Protocolo de Kyoto é um dos acordos de maior importância, pois é considerado o marco inicial do Mercado de Carbono, o qual se configura como um mercado de compra e venda de licenças para emissões ou reduções de emissões, que são ou distribuídas por um órgão regulador ou geradas por projetos que fazem a redução de emissões dos GEEs (PETERS- STANLEY; YIN, 2013), mas que também pode se dividir em diferentes formas, tamanhos e regulamentações (GODOY; SAES, 2015).

Este mercado se demonstra de fundamental importância no que diz respeito às políticas de redução de emissões dos GEEs, pela forma que se desenvolve e por estar inserido em um novo contexto de mecanismos de proteção ambiental.

Como forma de desenvolvimento do mercado de carbono, Kyoto criou três instrumentos denominados "instrumentos de flexibilização", que possibilitaram a participação de países que, na época não estavam obrigados a cumprir metas de redução de emissões. Trata-se d a implementação conjunta, do comércio de emissões e do Mecanismo de Desenvolvimento Limpo (MDL), sendo o MDL o instrumento que permite que o Brasil negocie suas licenças de redução de emissão (CGEE, 2010). 
Considerando a participação de países com diferentes contextos sociais, é importante ter em mente a conjuntura socioambiental na qual este mercado está inserido. O Brasil, por exemplo, tem como grande parte de sua população as comunidades tradicionais, sobretudo na Amazônia, as quais se relacionam diretamente com os espaços e as atividades que resultam nas reduções de emissão dos GEE.

Diante disso, o presente artigo tem como objetivo descrever como se desenvolve o mercado de carbono, a nível global e nacional, de modo a explicar como o modo de operacionalização deste instrumento promove o desenvolvimento de uma política de redução das emissões e proteção contra as mudanças climáticas.

Para tal, a estratégia metodológica utilizada foi uma pesquisa bibliográfica e documental sobre a regularização global e local do dispositivo descrito, resultando em uma abordagem descritiva.

Primeiramente será explanada a origem do Mercado de Carbono, a fim de analisar os acordos que trouxeram a sua institucionalização e o envolvimento dos países partes. Em seguida, será analisada a forma como o mercado se desenvolve em nível global, para, enfim, abordar o cenário nacional, de modo a demonstrar a importância deste mecanismo para o combate as emissões de GEEs.

\section{A origem do mercado de carbono}

Com o intuito de tratar sobre o desenvolvimento sustentável e a preservação ambiental, houve a necessidade da criação de mecanismos globais que versassem sobre a responsabilidade dos países em relação a questão ambiental, sobretudo das mudanças climáticas, devido à discussão sobre os impactos da poluição e o aquecimento global, que levaria a elevação da temperatura média global de 1,5 para 6 graus célsius até o ano de 2100. (IPCC, 2001).

Segundo Viola (2002), por estarem vinculados a um bem público global - a atmosfera - as mudanças climáticas culminaram por legitimar uma certa quebra da soberania e autonomia dos estados para tratar sobre tais questões.

Em verdade, a noção de cooperação internacional para tratar da questão ambiental envolvendo as mudanças climáticas tem relação com o enfoque teórico de Ostrom (1990), a qual trata dos bens ambientais como bens comuns/de acesso comum, que necessitam de uma ação coletiva dos sujeitos que interagem com este meio, de modo a evitar que tragédias venham 
a ocorrer.

Diante disso, foi criado o Painel Intergovernamental sobre Mudanças Climáticas (IPCC) em 1988, pelo Programa das Nações Unidas para o Meio Ambiente (PNUMA e pela Organização Mundial de Meteorologia (OMM). O painel realiza uma avaliação dos conhecimentos sobre as mudanças climáticas, trazendo grandes subsídios para a Convenção Quadro das Nações Unidas sobre Mudanças Climáticas - UNFCCC (VIOLA, 2002).

A UNFCCC tem como objetivo estabilizar a concentração dos GEEs na atmosfera por ações de mitigação dos países signatários (ONU, 2012). Nesta perspectiva, foi instituída a criação da Conferência das Partes (COP), que é um órgão supremo de decisões dentro da Convenção, que realiza reuniões anuais para debater as evoluções políticas na esfera da norma internacional e estabelecer novas metas na política ambiental de mudanças climáticas entre os países participantes (GODOY; SAES, 2015).

A UNFCCC estabeleceu princípios, dentre eles, o da precaução, de que os países devem tomar medidas a fim de evitar maiores danos as mudanças do clima, e o da responsabilidade comum, que versa sobre a ação das partes com base na equidade, visto que a atmosfera se constitui um bem comum, devendo ser preservada de acordo com a capacidade de cada país (OLIVEIRA; MIGUEZ; ANDRADE, 2018).

Neste cenário, em 1997, foi formulado o Protocolo de Kyoto, estabelecendo metas de redução de emissões para os países do Anexo I da Convenção Quadro, membros da Organização para a Cooperação e o Desenvolvimento Econômico (OCDE). Este protocolo estabeleceu, para os países do Anexo I, o primeiro período de compromisso, de 2008 a 2012, com meta de redução de 5,2\% da média global de GEEs em relação aos níveis de 1990. A norma passou a vigorar somente em 2005, ao atingir 55 ratificações, buscando atingir 55\% do total de emissões do GEEs (ONU, 1992). A partir de 2012, foi estabelecido, na COP 17, o segundo período de compromisso, vigorando de 2013 a 2020, com meta de redução de $18 \%$ em relação aos níveis de emissão de 1990 (ONU, 2012).

Kyoto criou três instrumentos denominados "instrumentos de flexibilização" com o objetivo de alcançar as metas de redução, quais sejam a implementação conjunta, o comércio de emissões e o Mecanismo de Desenvolvimento Limpo - MDL (SILVA, ROCHA FREIRA e BASSETO, 2012, p. 10). Cada instrumento possui uma forma de operacionalização, seja no âmbito dos países desenvolvidos, do Anexo I do Protocolo, ou no dos países em desenvolvimento, mas ambos promovem uma eficiência econômica ao induzir a redução dos 
GEEs onde há os menores custos, além de contribuir para que os países realizem investimento em tecnologia de menor emissão, adequando a sociedade a um melhor padrão de consumo (OLIVEIRA; MIGUEZ; ANDRADE, 2018).

Considerando a proximidade do encerramento do segundo período de compromisso do Protocolo de Kyoto, como resultado da $21^{\text {a }}$ Conferência das Partes (COP21), foi firmado, em 2015, o Acordo de Paris, pelo qual os países decidiram que passariam a estabelecer suas próprias metas de redução de emissão, a qual seria válida tanto para os países do Anexo I, para os demais, todos sendo responsabilidades pelas Contribuições Nacionalmente Determinadas Pretendidas (Intended Nationally Determined Contributions - iNDCs) (CORAZZA; SOUZA, 2017).

O mercado de carbono surge num contexto em que a problemática das mudanças climáticas é considerada uma externalidade negativa, uma falha de mercado gerada pelas ações humanas, o que torna necessário mecanismos que as internalizem (GODOY, 2017).

As principais teorias que tratam sobre essa internalização, relacionando as questões ambientais e sociais com as questões econômicas são as dos economistas Arthur C. Pigou (1959) e Ronald H. Coase (1960), que abordam a correção das externalidades com diferentes concepções. Nessa perspectiva, Pigou (1959) defende a necessária imposição de uma taxa ao poluidor, na tentativa de re-estabelecer o equilíbrio paretiano. ${ }^{1}$ Em verdade, autores como Rosanvallon (1981, p. 60) consideram que as externalidades representam um mau funcionamento do mercado que podem dar origem a decisões localmente racionais mas globalmente aberrantes. Justifica-se, assim, a intervenção do Estado sobre domínio econômicoambiental, no sentido de obrigar a internalização dos custos sócio-ambientais, através da cobrança um preço estatal equivalente aos danos acarretados a terceiros.

Partidário de uma opinião contrária à defendida por Pigou, o Prêmio Nobel de economia, Ronald Coase, funda uma teoria econômica voltada para a ampliação do mercado e abstenção do Estado. Defendendo a bilateralidade das relações econômicas, Coase fornece uma alternativa à internalização, através da imposição de um valor aos bens (MORENO, 1992), fixando direitos de propriedade (COURET, 1992) e, pela livre negociação entre as partes estipula-se, por exemplo, quanto vale para o poluidor deixar de poluir e quanto vale para a vítima não sofrer a poluição despejada pelo primeiro. 
1 Segundo a teoria do Ótimo de Pareto, o mercado atinge um grau máximo de equilíbrio quando qualquer mudança imposta à produção, seja na aplicação dos recursos, ou na técnica empregada, não pode ser implantada sem que tenha como conseqüência um excessivo aumento gratuito de custos, em detrimento de uma outra atividade. CRISTIANE DERANI, trata da questão explicando que “... a economia de mercado atinge o seu grau ótimo quando realiza uma satisfatória relação entre o uso de um recurso natural e sua conservação, encontrando um preço que permita a utilização do bem ao mesmo tempo em que o conserva." (DERANI, 1997, p. 131).

Parte-se do princípio de que nada tem um custo neutro no mercado, devendo o mercado passar a considerar tais custos, a partir da abertura de canais de negociação entre as partes (COASE, 1960).

Nesta perspectiva, explica Altamirano (2001, p. 57) que:

\begin{abstract}
"Privadamente las partes involucradas pueden negociar efectuándose concesiones recíprocas: el afectado ofrecería un precio al afectante hasta el punto en que el beneficio marginal del afectado iguale al costo marginal de efectuar el pago indemnizatorio. Por su parte el contaminador reducirá su nivel de contaminación al punto que su pérdida marginal - generada por la modificación de su actividad - iguales al beneficio marginal que obtiene por el cobro. Esto significa que los sujetos sin requerir la intervención estatal podrían resolver sus diferencias mediante una indemnización de daños y prejuicios"
\end{abstract}

Dessa maneira, o Mercado de Carbono encontra-se inserido em uma conjuntura na qual as normas de comando e controle, introduzidas nos países nos anos 70 e 80, tornam-se insuficientes e deficientes para a proteção ambiental (TUPIASSU, 2006). Assim, surge a introdução de instrumentos econômicos, que têm como objetivo incentivar a prática de conservação da natureza por aqueles que produzem os serviços ambientais (DERANI; JODAS, 2015).

O Mercado de Carbono trabalha, portanto, dentro de uma lógica econômica de permissões negociáveis e comércio de emissões (GODOY; SAES, 2015), onde a comercialização dos certificados de redução de emissões de GEEs se encontra dentro de um limite estabelecido pelo estado, mas que quem coloca o preço da externalidade positiva gerada é o próprio mercado, segue uma racionalidade mista, estatal e mercadológica (CGEE, 2010).

\title{
3. Mercado de Carbono em âmbito global
}

O Protocolo de Kyoto estabeleceu três instrumentos de flexibilização: a implementação conjunta, o comércio de emissões e o Mecanismo de Desenvolvimento Limpo - MDL, cada 
qual com a sua particularidade na operacionalização dos procedimentos de compra e venda de licenças para emissões ou reduções de emissões.

A implementação conjunta e o comércio de emissões são instrumentos que envolvem somente os países do Anexo I, os países desenvolvidos. São instrumentos a partir dos quais os países, por sua própria iniciativa, cumprem com as metas de redução do Protocolo. A implementação conjunta permite que os países do Anexo I realizem a compensação de suas emissões adquirindo unidades de redução de emissões de outro país do grupo, devendo todos as verbas obtidas com a negociação ser investidas em projetos de redução de emissão. $\mathrm{O}$ comércio de emissões permite que os países do Anexo I comercializem as reduções que excederam as suas metas de reduções, o que é chamado de sistema cap and trade (IPEA, 2009).

Já o MDL é um instrumento que permite que as reduções ocorram em diferentes países e projetos, inclusive naqueles países que não compõem o Anexo I do Protocolo, como é o caso do Brasil. Por este mecanismo os países desenvolvidos podem realizar negociações de reduções certificadas de emissões (RCE) com os países não Anexo I, ao invés de realizar a própria redução de emissões, o que demonstra a cooperação internacional no cumprimento de transferência de recursos financeiros que visam auxiliar a implementação de programas de redução de emissões nos países que não se encontram elencados no Anexo I.

A obtenção de créditos de carbono depende, em muito, do atendimento aos critérios formais e técnicos estipulados pelas normas que regem o instituto.

O artigo 12 do Protocolo de Kyoto determina, por exemplo, que as reduções de emissões resultantes de cada atividade de projeto devem ser certificadas por entidades operacionais a serem designadas pela Conferência das Partes, sendo obrigatória a participação voluntária da entidade, independentemente de previsão legal interna.

A norma internacional exige, ainda, que os projetos certificados oportunizem benefícios reais, mensuráveis e de longo prazo relacionados com a mitigação da mudança do clima, e que as reduções de emissões sejam adicionais as que ocorreriam na ausência da atividade certificada de projeto.

Assim, no MDL há um requisito de adicionalidade, o que quer dizer que há uma referência adotada quanto as emissões que ocorreriam mesmo se o projeto de MDL não fosse adotado. Isso implica em somente ser possível considerar as reduções de emissões dos projetos de MDL se estas forem adicionais àquelas que já ocorreriam normalmente, ou seja, se as emissões forem menores do que as fixadas na linha de base de referência. Ocorre que há uma 
dificuldade na demonstração da linha de base, mas que não pode gerar malefícios a aplicação dos projetos de MDL (CGEE, 2010).

O modo como as reduções são calculadas nos países Anexo I e países não-Anexo I um é distinto. Nos países Anexo I a base para o cálculo da redução de emissões é realizada pela soma das emissões nacionais de todos os gases em todos os setores industriais, em relação com as bases de emissões em 1990, de modo que uma meta percentual quantitativa seja atingida. Nos países não-Anexo I a redução é calculada considerando projetos individuais, tendo como referência emissões que ocorreriam se os projetos de MDL não fossem instituídos (CGEE, 2010).

Na prática, o Mercado de Carbono ganhou duas perspectivas, podendo-se dizer que o sistema é dividido em dois tipos, Regulado (Kyoto-compliance) e Voluntário (Não Kyotocompliance). No mercado regulado os créditos são negociados com o objetivo de abater as metas de reduções de acordo com o que fora estabelecido em Kyoto, no mercado voluntário as metas abatidas são por parte voluntária das empresas e governos, sem sofrer e regulamentação do Protocolo (SILVA, ROCHA FREIRA e BASSETO, 2012, p. 11).

Assim, as negociações podem ocorrer dentro do Protocolo, no mercado Europeu, que segue um sistema de licenças de emissões, ou em outros mercados, em diversos setores da economia, como energia e florestamento (GODOY; SAES, 2015).

No mercado de carbono voluntário há os padrões de certificação emitidos por terceiros, os quais realizam auditoria e monitoram periodicamente os projetos certificado, para analisar as conformidades e a confiabilidade (MACKERRON et al., 2009). Já no mercado regulado as certificações de redução são emitidas por um Conselho Executivo que supervisiona a execução do MDL, em conjunto com uma Entidade Operacional Designada (EOD) para validar os projetos de MDL e verificar e certificar as reduções oriundas do Projeto e uma Autoridade Nacional Designada (AND) que autoriza as entidades do país a participar e receber créditos de um Projeto de MDL (SILVA, ROCHA FREIRA e BASSETO, 2012).

O Mercado de Carbono Europeu tem como objetivo auxiliar os países a atingirem suas metas fixadas em Kyoto. Para que isso seja possível, os países da União Europeia podem usar créditos de carbono de MDL, o que fora instituído pelo regime regulatório do o Sistema de Comércio de Emissões da União Europeia, o "Linking Directive". Além disso, neste mercado os membros devem desenvolver um "National Allocation Plan - NAP" (Plano Nacional de Alocação), que estabelece a quantidade de licenças de emissões dos GEEs a serem distribuídas 
aos setores industriais (GODOY; SAES, 2015).

Além do Marcado de Carbono Regulado dentro do sistema do Protocolo de Kyoto e o Europeu, existem outros mercados, como o Regional Greenhouse Gas Initiative (RGGI), o Western Climate Initiative (WCI), o Certified Emission Reduction Unit Procurement (CERUPT), entre outros, os quais possuem seu regime próprio de metas e regulamentações (CGEE, 2010).

Apesar de não se tratar de um mercado com um fim meramente mercadológico, o Mercado de Carbono possui um dinâmica similar a lógica mercadológica, com um desempenho dependente de seus compradores e vendedores, o que leva a haver uma variação de seus preços e na sua demanda, de acordo com o interesse de os países em atingirem suas metas, bem como com o engajamento na criação de projetos de MDL (GODOY; SAES, 2015).

O montante de créditos de carbono emitidos e projetos de MDL concluídos, por exemplo, teve um grande acréscimo, ao final do primeiro período de compromisso, momento em que o valor de mercado de tais commodities experimentou uma grande alta.

O mesmo aconteceu em 2019, com a aproximação do final do segundo período de compromisso, que igualmente implicou em um forte aumento do valor de comercialização dos créditos.

Os objetivos de redução de emissões permanecem, em sua maioria, em aberto, iniciando-se uma nova era com as perspectivas geradas pelo Acordo de Paris.

Os mercados, ademais, ainda sofrem grandes dificuldades, principalmente relacionadas ao desempenho e custos de transação, tendo em vista que demandam altos custos de implementação (GODOY, 2013).

\section{O Mercado de Carbono no Brasil}

O Brasil utiliza como instrumento de flexibilização de participação no Mercado de Carbono o MDL, já que é país não-Anexo I do Protocolo. Durante a institucionalização do MDL nas negociações internacionais caracterizou-se como pioneiro no desenvolvimento de projetos (BITTENCOURT; BUSH; CRUZ, 2018).

O Brasil oficializou seus compromissos de redução de emissões dos GEE junto À Convenção Quadro das Nações Unidas sobre Mudanças Climáticas por meio da Política Nacional sobre Mudança do Clima (PNMC), que fora instituída pela Lei $\mathrm{n}^{\circ}$ 12.187/2009. (Brasil, 2009). 
No que diz respeito a avaliação dos projetos de MDL a Autoridade Nacional Designada (AND) no Brasil anteriormente instituída fora a Comissão Interministerial de Mudança Global do Clima (CIMGC), que, no atual governo presidencial, vem sendo desempenhada pela Coordenação-Geral do Clima, da Secretaria de Políticas para a Formação e Ações Estratégias, de acordo com o Decreto ${ }^{\circ}$ 9.759/2019.

Para que as reduções certificadas de emissões (RCE) sejam emitidas há um cronograma a ser seguido. Primeiramente é necessário a elaboração de um documento de concepção de projeto, que precisa ser aprovado e validado pela AND, para posterior registro no Conselho executivo, a fim de realizar a verificação e certificação das reduções de emissões (BITTENCOURT; BUSH; CRUZ, 2018).

O Brasil encontra-se em terceiro lugar, atrás apenas da China e da Índia, no número de projetos de MDL aprovados. De acordo com o banco de dados de busca de projetos de MDL da UNFCCC, até 2020, o Brasil registrou 385 projetos.

Ainda que seja um dos maiores participantes do sistema, trata-se de número ainda restrito diante da diversidade de recursos naturais do país e da diversidade de áreas de atuação para os projetos de redução de emissão de GEEs.

Em verdade, a China possui quase dez vezes mais projetos aprovados de MDL que o Brasil, e a Índia possui quase cinco vezes mais.

Além disso, apesar da diversidade de recursos naturais no estado brasileiro, e da potencialidade de participação do país no mercado de carbono em diversos eixos da economia, os projetos de MDL existentes no Brasil concentram-se essencialmente no setor da energia, sendo o país extremamente beneficiado por sua matriz energética de produção.

Ademais, em que pese a riqueza natural existente da região amazônica, a região Norte do país é o local onde, até o momento, pouquíssimos projetos foram desenvolvidos.

De fato, grande parte da área florestal existente é atacada por desmatamento e degradação, o que contribui para o Brasil ser um dos maiores emissores de $\mathrm{CO} 2$ em âmbito global (IPCC, 2015). Isso demonstra a necessidade de o país alterar suas práticas econômicas, para que haja uma maior redução de emissões e não um aumento do nível.

A partir de 2020, com a nova sistemática adotada no Acordo de Paris, o Brasil se engaja a reduzir suas emissões em 37\%, tendo por base os parâmetros de 2005. Nessa perspectiva, grandes esforções deverão ser feitos.

Os créditos de carbono florestais, por exemplo, representam grande potencialidade, vez 
que correspondem a menos de $1 \%$ do total de projetos existentes na atualidade.

A modalidade enfrenta, porém, diversos desafios, principalmente porque não permite considerar atividades de conservação ou manejo de estoques florestais já existentes, tornando obrigatório o estabelecimento antrópico de novas florestas em áreas que não continham florestas ou o reflorestamento de áreas desflorestadas há muito tempo.

Ademais, há grande dificuldade de transacionar créditos de carbono florestal nos mercados europeu e demais mercados voluntários.

Considerando tais limites, desenvolveu-se no âmbito da $19^{a}$ Conferência das Partes (COP19) uma estratégia voltada à redução das emissões de desmatamento e degradação florestal, que acopla sistemáticas de conservação dos estoques de carbono florestal, manejo sustentável de florestas e aumento dos estoques de carbono. Tudo isso encontra-se conhecido sob a sigla REDD+, em fase de alargamento da aplicação em âmbito nacional.

Dentro de todo esse cenário, o Novo Código Florestal (Lei $n^{\circ}$ 12.651/2012) fez referência ao mercado de carbono, em seu Artigo 41, ao estabelecer, no Programa de apoio e incentivo à conservação do meio ambiente, a previsão das ações de sequestro, conservação, manutenção e diminuição dos fluxos de carbono, que integram as ações realizadas nos projetos de redução de emissão.

Curioso observar, porém, que tal norma nacional considerou, no parágrafo $4^{\circ}$ do art. 41 , as atividades de manutenção das Áreas de Preservação Permanente, de Reserva Legal e de uso restrito "elegíveis para quaisquer pagamentos ou incentivos por serviços ambientais, configurando adicionalidade para fins de mercados nacionais e internacionais de reduções de emissões certificadas de gases de efeito estufa".

Considerando que as Áreas de Preservação Permanente, de Reserva Legal e de uso restrito têm sua preservação determinada por lei, é possível que tal norma esbarre nos limites estabelecidos no Protocolo de Kyoto em relação à voluntariedade, aos benefícios reais e à adicionalidade.

Será necessário verificar, na prática, como o benefício real e a adicionalidade serão aferidas, considerando que a manutenção das as Áreas de Preservação Permanente, de Reserva Legal e de uso restrito já se enquadram dentre as obrigações primordiais dos proprietários e, além de tudo, tratam-se de obrigações de preservação legalmente definidas.

Entretanto, também devem ser levados em consideração os processos socioecológicos envolvidos dentro de uma dinâmica do desenvolvimento sustentável, na qual se insere o 
Mercado de Carbono.

É importante uma tomada de consciência sobre o fato de que atividades que levam as reduções de emissões, sobretudo quando estas atividades estão relacionadas aos créditos de carbono florestais, contam com as comunidades tradicionais que ali habitam, as quais, por sua atividade habitual, já têm em seu meio de vida uma forma de promoção do desenvolvimento sustentável (SAMPAIO; WORTMANN, 2014).

Pelo modo de vida que tais comunidades tradicionais têm em sua cultura, se faz necessário uma adaptação dos instrumentos econômicos as suas realidades, mantendo as suas atividades tradicionais, de modo a garantir a participação efetiva e o acesso e ocupação de seus territórios.

Assim, a lógica do mercado de carbono não deve estar restrita a mercantilização da natureza, mas sim aos arranjos sociais construídos, interagindo com as realizadas culturais das comunidades tradicionais, de modo a ter uma interação com os processos socioecológicos.

\section{Conclusão}

A instituição do Mercado de Carbono pelos acordos internacionais sobre mudanças climáticas trouxe a possibilidade de instrumentos econômicos como estratégia de fomento para a redução das emissões dos GEEs, em países desenvolvidos ou em desenvolvimento, como o Brasil, o qual por sua grande diversidade de recursos naturais mostra-se como um grande promotor de Reduções Certificadas de Emissões (RCE).

Dentro do sistema regulado ou voluntário, a sistemática para que haja uma redução dos níveis de emissões é promissora, tendo em vista que há um aparato organizacional dentro do Mercado de Carbono, para que o sistema de permissões negociáveis seja efetivo e o fim maior, qual seja a proteção dos recursos naturais, por meio dos incentivos monetários, seja alcançado.

Apesar de haver grandes desafios, sobretudo no que diz respeito aos custos de transação para implementação dos projetos de MDL, a lógica do Pagamento por Serviços Ambientais (PSA) se demonstra um importante meio para que a preservação ambiental seja alcançada, tendo em vistas que os sistemas de comando e controle têm se demonstrado ineficazes e ineficientes e os instrumentos econômicos e tributários como incentivos a preservação têm alcançado maiores benefícios quanto as políticas de preservação ambiental.

Deste modo, a fim de que a política de redução de emissões acordada entre os países do Protocolo de Kyoto seja alcançada, bem como para que os países cumpram suas próprias metas de redução, a seu benefício, se faz necessário um engajamento desses diante dos instrumentos 
postos como alternativas, por meio de investimentos e incentivos governamentais na criação de projetos e na participação dos acordos internacionais, a fim de acompanhar como tal política tem alcançado seus objetivos.

O Protocolo de Kyoto, ainda que demonstre um grande avanço, pois representa a definitiva introdução de instrumentos econômicos no direito ambiental internacional, teve efeitos limitados e o mercado de carbono entra em uma nova era com as perspectivas adotadas pelo Acordo de Paris.

O fomento das políticas de redução de emissões a partir do desenvolvimento de uma economia ecológica e com perspectivas de valorizar os ricos ativos ambientais existentes no Brasil se faz, porém, necessário, tendo em vista que, para a sobrevivência humana é preciso que os recursos naturais, bem como a condição climática não sejam prejudicados. Mas, não só isso, é preciso que sejam levadas em consideração as comunidades que participam, intrinsicamente, da preservação dos recursos, que se caracterizam como principais atores nas práticas de redução.

\section{REFER̂̂ECIAS}

ALTAMIRANO, Alejandro C. El derecho constitucional a un ambiente sano, derechos humanos y su vinculación con el derecho tributario. Revista Tributária e de Finanças Publicas, São Paulo, v. 9, n.40, p. 31-91, set./out. 2001.

ALTMANN, Alexandre. Princípio do preservador-recebedor: contribuições para a consolidação de um novo princípio de direito ambiental a partir do sistema de pagamento por serviços ambientais. In: SILVEIRA, Clóvis Eduardo Malinverni da. (Org.). Princípios do direito ambiental: atualidades. 1ed.Caxias do Sul: EDUCS Editora da Universidade de Caxias do Sul., 2012, v. 1, p. 125-162.

BANCO MUNDIAL. O preço do Carbono. 2017. Disponível em: <https://www.worldbank.org/en/results/2017/12/01/carbon-pricing>. Acesso em: Acesso em 7 julho. 2020 .

BITTEnCOURT, Sonia; BUSCH, Susanna; CRUZ, Márcio. O Mecanismo de Desenvolvimento Limpo no Brasil. In: O Legado do MDL: impactos e lições aprendidas a 
partir da implementação do mecanismo de desenvolvimento limpo no Brasil . IPEA. Brasília, 2018.

BRASIL. Decreto No 5.445, De 12 De Maio De 2005. Promulga o Protocolo de Quioto à Convenção-Quadro das Nações Unidas sobre Mudança do Clima. Diário Oficial da União, Poder Executivo, Brasília - DF, 13 de Maio de 2005.

BRASIL. Lei no 9.759, de 11 de abril de 2019. Brasília: DOU, 2019. Disponível em: < http://www.planalto.gov.br/ccivil_03/_Ato2019-2022/2019/Decreto/D9759.htm>. Acesso em: 13 jun. 2020.

BRASIL. Lei $\mathbf{n}^{\mathbf{0}}$ 12.651, de 25 de maio de 2012. Brasília: DOU, 2012. Disponível em: < http://www.planalto.gov.br/ccivil_03/_ato2011-2014/2012/lei/112651.htm>. Acesso em: 13 jun. 2020.

BRASIL. Lei no 12.187, de 29 de dezembro de 2009. DOU, 2009. Disponível em: <http://www.planalto.gov.br/ccivil_03/_Ato2007-2010/2009/Lei/L12187.htm>. Acesso em: 13 jun. 2020.

CAVALCANTI, Clóvis. Concepção da economia ecológica: suas relações com a economia dominante e a economia ambiental. Estudos avançados. V. 24, p. 53-67, 2010.

CENTRO DE GESTÃO E ESTUDOS ESTRATÉGICOS - CGEE. Manual de capacitação sobre Mudança climática e projetos de mecanismo de desenvolvimento limpo (MDL). Brasília, 2010.

COASE, Ronald H. The Problem of Social Cost. Journal of Law and Economics, 1960.

CONVENÇÃO QUADRO DAS NAÇÕES UNIDAS SOBRE MUDANÇA DE CLIMA CQNUMC. Protocolo de Kyoto à Convenção sobre Mudança do Clima, 1997.

CONVENÇÃO QUADRO DAS NAÇÕES UNIDAS SOBRE MUDANÇA DE CLIMA CQNUMC. Banco de dados de Projetos de MDL. Disponível em: < 
https://cdm.unfccc.int/Projects/projsearch.html>. Acesso em: Acesso em: 13 jun. 2020.

COURET, Alain. La proprieté et l'organisation de la production en économie libérale. In : FARJAT, G. et REMICHE, B. Liberté et Droit Économique. Bruxelles : De Boeck, 1992.

DERANI, Cristiane. Direito ambiental econômico. São Paulo: Max Limonad, 1997.

DERANI, Cristiane.; JODAS, Natália. Pagamento por serviços ambientais (PSA) e a racionalidade ambiental: aproximações. Scientia Iuris, Londrina, v. 19, n. 1, p. 9-27, jun. 2015. Doi: 10.5433/2178-8189.2015v19n1p9

GODOY, Sara. Projetos de redução de emissões de gases de efeito estufa: desempenho e custos de transação. R. Adm, São Paulo, v. 48, n. 2, p. 310-326, abril/maio/jun 2013.

GODOY, Sara; SAES, Maria. Cap-and-trade e projetos de redução de emissões: comparativo entre mercados de carbono, evolução e desenvolvimento. Ambiente e Sociedade, v. XVIII, n. 1np, p. 141-160, jan-mar 2015.

GUTIERREZ, Maria. O Brasil e o Mercado de Carbono. IPEA. Dez, 2009

IPCC. Climate change 2014: synthesis report. Contribution of Working Groups I, II and III to the Fifth Assessment Report of the Intergovernmental Panel on Climate Change Switzerland, 2015.

MACKERRON, Georde; EGERTON, Catrin; GASKELL, Christopher;PARPIA, Aimie; MOURATO, Susana. Willingness to pay for carbon offset certification and co-benefits among (high-)flying young adults in the UK. Elsevier Ltd. 2008.

MORENO, José Luis Serrano. Ecologia y derecho. Granada: Comares, 1992

ONU - ORGANIZAÇÃO DAS NAÇÕES UNIDAS. Acordo de Paris. CQNUMC, 2015.

Disponível em: <https://bit.ly/2Iz1X0N>. Acesso em 7 julho. 2020.

PETERS-STANLEY, M., \& YIN, D. (2013). Maneuvering the mosaic: state of the voluntary

Revista de Direito Ambiental e Socioambientalismo | e-ISSN: 2525-9628 | Encontro Virtual | v. 6 | n.

2 | p. $93-108$ | Jul/Dez. 2020. 
carbon markets. 2013. Disponível em: http://www.foresttrends.org/documents/files/doc_3898.pdf. Acesso em 7 de julho de 2020.

PIGOU, Arthur Cecil. The economics of welfare. 1959. Disponível em: <http://www.econlib.org/library/NPDBooks/Pigou/pgEW0.html>. Acesso em: 7 jun. 2020.

ROSANVALLON, Pierre. La crise de l'État-providence, Paris: Seuil, 1981

SILVA, Christian; FREIRE JR, Weimar; BASSETO, Luci. Mercado de Carbono e instituições: oportunidades na busca por um novo modelo de desenvolvimento. Interciência, vol. 37, n. 1, p. 08-13. 2012.

SOUZA, Maria; CORAZZA, Rosana. Do Protocolo Kyoto ao Acordo deParis: uma análise das mudanças no regime climático global a partir do estudo da evolução de perfis de emissões de gases de efeito estufa. Desenvolvimento e meio ambiente, v. 42, p. 52-80, dez. 2017. DOI: 10.5380/dma.v42i0.51298.

VEIGA, José Eli da. Sustentabilidade: a legitimação de um novo valor. Editora Senac. $2^{\text {a }}$ ed. São Paulo, 2010.

VIOLA, E. O regime internacional de mudança climática e o Brasil. Revista Brasileira de Ciências Sociais, (17)50, 25- 46, 2002. Doi: 10.1590/S0102-69092002000300003 